\title{
TUNING OF RESONANCE FREQUENCY IN ARRAY OF SPLIT-RING RESONATORS IN TERAHERTZ RANGE
}

\author{
G. Šlekas, Ž. Kancleris, and D. Seliuta \\ Center for Physical Sciences and Technology, A. Goštatuto 11, LT-01108 Vilnius, Lithuania \\ E-mail: slekas@pfi.lt
}

Received 18 November 2013; accepted 4 December 2013

\begin{abstract}
A numerical investigation of individual symmetric and asymmetric SRRs and planar arrays of SRRs is performed using the finite-difference time-domain method. The types of current resonances in such structures are determined. The relevance between the band-stop filtering effect in pulse transmission and the current resonances within the SRR is identified. Dependence of the resonant frequency on the size of the SRR is established. The tuning of the resonance frequency of the varactor-loaded SRR array is carried out by changing the depletion capacitance of the Schottky barrier.
\end{abstract}

Keywords: metamaterial, split-ring resonators, terahertz, band-stop filter, resonance tuning

PACS: 81.05.Xj, 78.67.Pt, 42.79.Ci

\section{Introduction}

Electromagnetic metamaterials with engineered unusual properties not readily existing in nature, such as a negative index of refraction, have attracted much attention from the scientific community in the past decades. The negative refraction has been demonstrated in the artificial medium consisting of thin stripes and split-ring resonators (SRRs) [1]. In principle, a SRR can also be used as an electrically resonant particle as it exhibits a strong resonant permittivity at the same frequency as the magnetic resonance [2]. Geometry of a SRR determines coupling of the resonator's fundamental mode to electric, magnetic or both electric and magnetic fields of the incident radiation [3]. Metamaterials are geometrically scalable and their resonant frequency can be tuned over several decades including the terahertz region in which passive photonic device radiation control still requires substantial development. Planar arrays of SRRs of an appropriate form [4] could find application for the development of novel devices operating in this frequency region and aimed at filtering, modulating, and switching the electromagnetic signal.
However, operational bands of metamaterials are limited to a narrow spectral region originating from resonant properties of their elements. Therefore, frequency tunable metamaterials have become an important area of interest since tuning the resonance frequency can effectively extend the operating bandwidth for certain applications. Numerous approaches to modify the electromagnetic response of metamaterials (i. e. frequency and/or amplitude of the resonance) have been demonstrated [5]. For many applications it is desirable to have fast realtime tunability of the resonant frequency of the resonators. Moreover, under monochromatic excitation the fast tunable filter may be easily converted to the fast modulator.

One of the most practical approaches of the tunable metamaterial filters and modulators is based on planar metallic resonator arrays placed on a semiconductor plate. The resonance depth may be varied by electrically depleting the Schottky barrier in the capacitive gap of the resonators [ [6]. It has been demonstrated that the modulation frequency may be increased by reducing the area of the Schottky barrier contacts 沛 or by integrating the high-electron 
mobility transistors with SRRs [8]. However, the demonstrated electrical methods suffer from a slow operation speed, while the optical methods, which are also sometimes used for resonance tuning [ 9 , 10], requiring a laser excitation source are impractical. On the other hand, it has been demonstrated that by integrating a surface-mounted varactor onto a resonator, its resonance frequency can be tuned significantly [11]. However, the frequency range of the reported structures does not exceed several GHz.

In this work, the planar arrays of SRRs targeted for the $\mathrm{THz}$ frequency regime have been simulated. We do not consider conventional split-ring resonators (two concentric rings with single gaps), but focus on simplified single-ring structures (symmetric and asymmetric) which may be readily loaded with biased varactor diodes. A few types of resonances have been investigated and compared in terms of potential applications in $\mathrm{THz}$ photonic devices. For all of our designs, simulations show a clear band-stop filtering effect in transmission.

\section{Calculation method}

We have modelled two SRR configurations: individual SRR and planar periodic SRR array attached to GaAs substrate. For the modelling of a periodic array of the SRR we have used the unit cell approach. Therefore, the only SRR has been modelled with periodic boundary conditions at the edges of the unit cell. In such a way the infinite plane of repetitive SRRs was modelled. For the calculation of the electromagnetic field components in the unit cell we have used a finite-difference time-domain (FDTD) method described in detail in [12]. A differentiated Gaussian pulse is applied as the current source to excite a wide spectra plane wave propagating away from the excitation plane. To truncate the computational domain and introduce absorption of the propagating pulse without reflections, uniaxial perfectly matched layers [12] were used.

The SRR considered is to be made from high conductivity metal stripes. Initially, in the individual SRR model, we assumed that the stripes are perfectly conductive, so the tangential electric field component within the stripe becomes zero. The electric current time dependence in the stripes was calculated according to the Ampere's law. Applying the Fourier transform, the power spectrum was obtained.
A more accurate model is used when a SRR lies on GaAs substrate in a plane normal to the pulse propagation direction forming a regular lattice. The dimensions of the lattice are of the same order as the SRR size, i. e. also much smaller than the radiation wavelength. Therefore, the macroscopic description of the metamaterial electromagnetic response is valid. We investigated the SRR made from gold. Whereas the stripes are very thin, hundreds of nanometres, they were included into modelling as two-dimensional conductive sheets [13].

The sizes of the FDTD discretization steps used in calculations are: $\Delta x=\Delta y=\Delta z=1 \mu \mathrm{m}, \Delta t=1.9 \mathrm{fs}$.

\section{Properties of individual SRR}

To find out how the SRR interacts with an electromagnetic pulse we investigated two types of individual SRRs (Fig. 1): (a) an asymmetric SRR (single split ring with one gap) and (b) a symmetric SRR (single split ring with two symmetrical gaps). The polarization of the electromagnetic wave is chosen so that the electric current in the structures is excited by the electric field only. Because the electric field of the excitation pulse is pointed to the same direction in both collateral stripes, the direction of passing current in both stripes, in respect of electrical circuit, is opposite. As a consequence, in certain points of the SRR the electric charge is accumulated. (a)

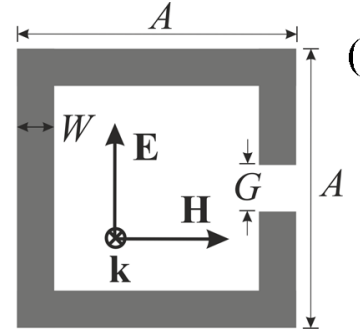

(b)

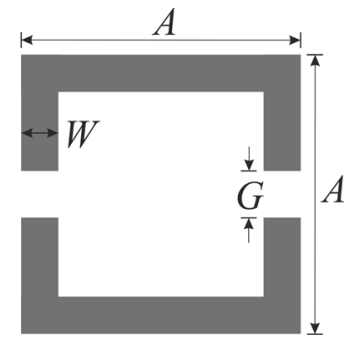

Fig. 1. Structures under investigation: (a) asymmetric SRR, (b) symmetric SRR. Modelling parameters: $A=36 \mu \mathrm{m}, W=1 \mu \mathrm{m}, G=2 \mu \mathrm{m}$, and unit cell size $50 \times 50 \mu \mathrm{m}^{2}$.

Initially, we calculated the dependence of the average current on coordinate within the stripes of the SRR. Calculation results in normalised units are shown in Fig. 2. The dependence starts from the top left corner of the SRR and goes in clockwise direction along the conducting stripe, as shown in the inset of the Figure. 


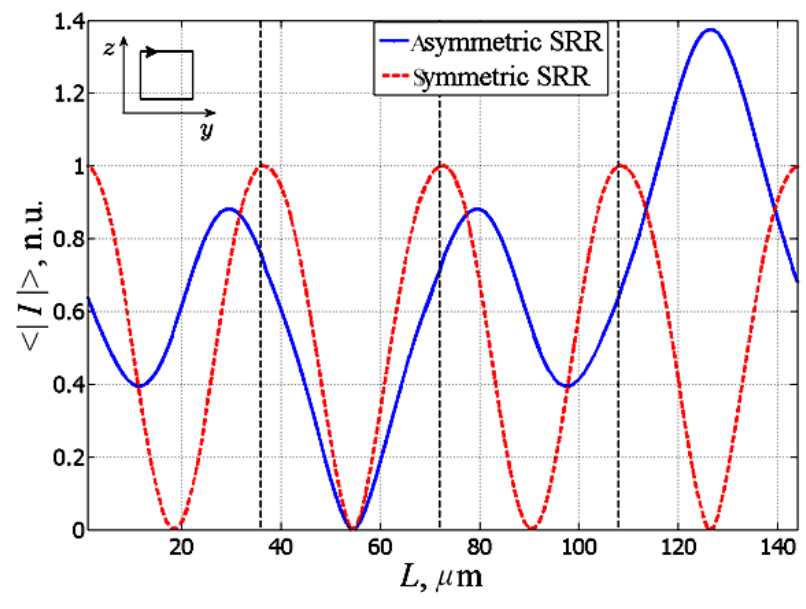

Fig. 2. Averaged current distributions in SRR stripes.

As one can see, the only point in the asymmetric structure where the current does not flow is the gap (Fig. 2, solid line). The maximum value of the current is observed in the centre of the left stripe. This can be explained by the fact that current is excited by the electric field that is parallel to the left stripe. In the symmetrical structure, the current does not flow in the gaps and in the central points of the horizontal stripes (Fig. 2, dotted line). It can be explained by the symmetry of the SRR in respect of the field. The current oscillates between the gaps and the symmetry points, forming peaks in the corners of the SRR.

Results of our further investigation reveal that there are two current modes in the SRR, appearing as resonances in the spectrum of the current: (1) a parallel mode originating from the influence of the source electric field and (2) a serial mode arising from the asymmetry of the SRR. The parallel mode is observed in both symmetric and asymmetric structures (Fig. 3). This mode is induced by the external electric field and vanishes fast after the excitation pulse travels away from the SRR. The serial mode occurs only in the asymmetric SRR.

As the parallel mode disappears, the current begins to flow as in the usual LC circuit, where the ring acts as an inductor and the gap acts as a capacitor. Although the amplitude of the serial current is much smaller than that of the parallel one, the significant contribution of the serial oscillations is seen in the spectrum due to its small damping and collecting the signal from the longer time domain.

The oscillation frequency of the current can be related to the length of the stripe segment, as shown in Table.

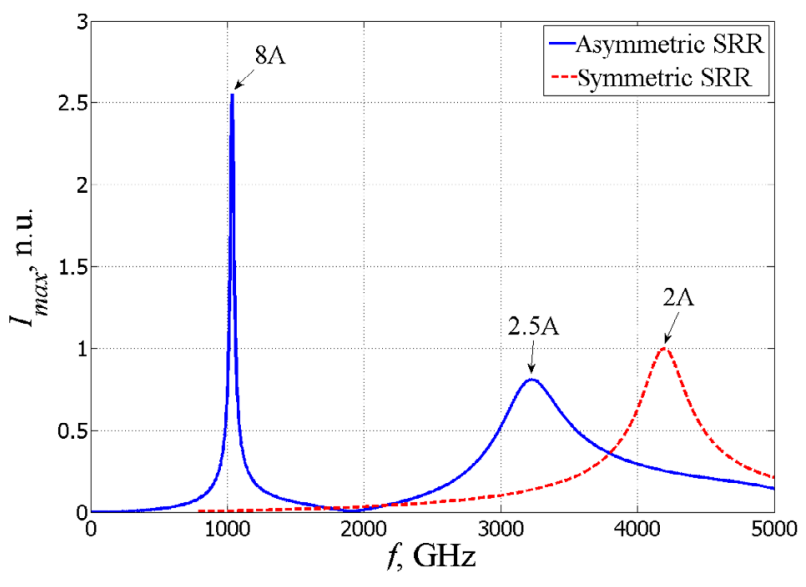

Fig. 3. The spectra of the current at the maximum amplitude position in symmetric and asymmetric SRRs. Arrows indicate the wavelength of particular resonance frequency.

Table. Current resonance frequency relation with the size of the SRR.

\begin{tabular}{ccc}
\hline & $\boldsymbol{f}_{\text {parallel }}$ & $\boldsymbol{f}_{\text {serial }}$ \\
\hline Symmetric & $c / 2 A\left(\varepsilon^{*}\right)^{1 / 2}$ & - \\
\hline Asymmetric & $c / 2.5 A\left(\varepsilon^{*}\right)^{1 / 2}$ & $c / 8 A\left(\varepsilon^{*}\right)^{1 / 2}$ \\
\hline
\end{tabular}

In Table, $c$ denotes a speed of light in vacuum, $\varepsilon^{*}$ is the effective dielectric constant of the substrate, expressed as follows:

$$
\varepsilon^{*}=\frac{\varepsilon+1}{2} \text {. }
$$

\section{Shifting resonance frequency of SRR array}

For practical applications SRRs are normally configured as planar arrays placed on the surface of a solid substrate. Investigation reveals that the current modes in the SRR are strongly associated with pulse transmission characteristics through the array of SRRs. The SRRs placed periodically on dielectric substrate shows good filtering features at the resonance frequency. In general, the frequency and amplitude of the resonance depends on the unit cell size as well; however, this dependence is not very strong. This illustrates results shown in Fig. 4, where the sizes of the SRR were chosen according to Table to get the resonance at $300 \mathrm{GHz}$. As one can see from the modelling results the actual frequency of the resonance is very close to the desired frequency.

SRRs presented in Fig. 1 may be loaded with varactor diodes for the resonant frequency tuning [14]. 


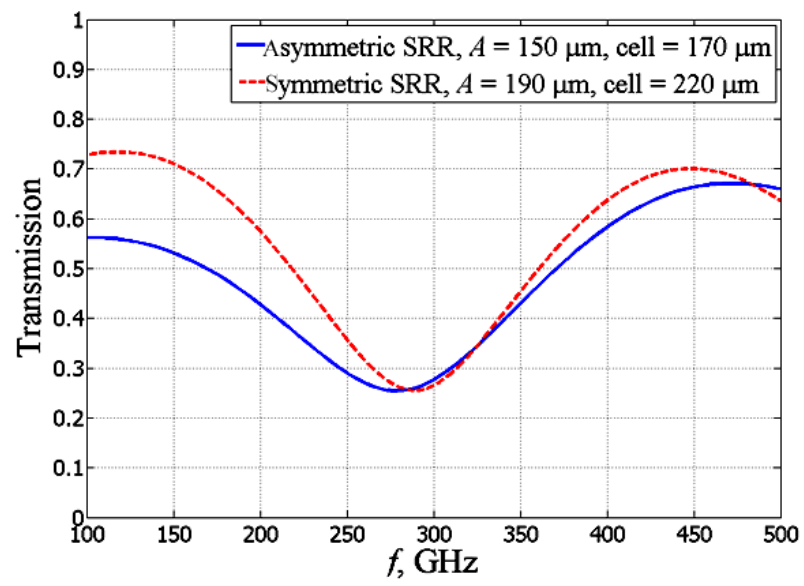

Fig. 4. The dependence of the transmitted amplitude through the array of the SRRs on frequency for symmetric and asymmetric structures. The dimension $A$ was chosen using formulas in Table to get resonances at $300 \mathrm{GHz}$. Modelling parameters: $W=4 \mu \mathrm{m}, G=2 \mu \mathrm{m}$, thickness of GaAs substrate $350 \mu \mathrm{m}, \varepsilon=12.85$.

Loading the SRR structure with discrete varactors is not directly applicable at terahertz frequencies due to small dimensions of the SRR. Therefore, we consider varactor diodes as integrated mesa structures fabricated on GaAs substrate. We model a Schottky barrier varactor fabricated under the stripe close to the one gap of the symmetric SRR structure (Fig. 1b). The Schottky contact area is $4 \times 4 \mu \mathrm{m}^{2}$. We assume that the varactor cut-off frequency is much higher than $300 \mathrm{GHz}$ [15] and its depletion capacitance can be changed with external reverse bias from 1.0 down to $0.25 \mathrm{fF} / \mu \mathrm{m}^{2}$ [15]. An additional capacitance added to the SRR shifts the resonance towards lower frequency; therefore, in order to return the resonance to the $300 \mathrm{GHz}$, the size of the SRR should be decreased. It is worthwhile to mention that such a structure becomes asymmetric. This is confirmed by the two resonances appearing in the transmission spectra (Fig. 5). The parallel current mode triggers the resonance near $300 \mathrm{GHz}$ whereas the serial current mode causes the resonance near $100 \mathrm{GHz}$. One can see that by decreasing varactors capacitance the resonance frequency shifts to the higher frequency. Relative change of the resonance frequency is $7.5 \%$ and the decrease of the transmitted amplitude at the central frequency $\left(C_{\mathrm{S}}=1.0 \mathrm{fF} /\right.$ $\mu \mathrm{m}^{2}$ ) resonance is roughly $9 \%$.

The serial mode can also be employed at $300 \mathrm{GHz}$. This demonstrates results shown in Fig. 6. The serial resonance frequency is shifted to

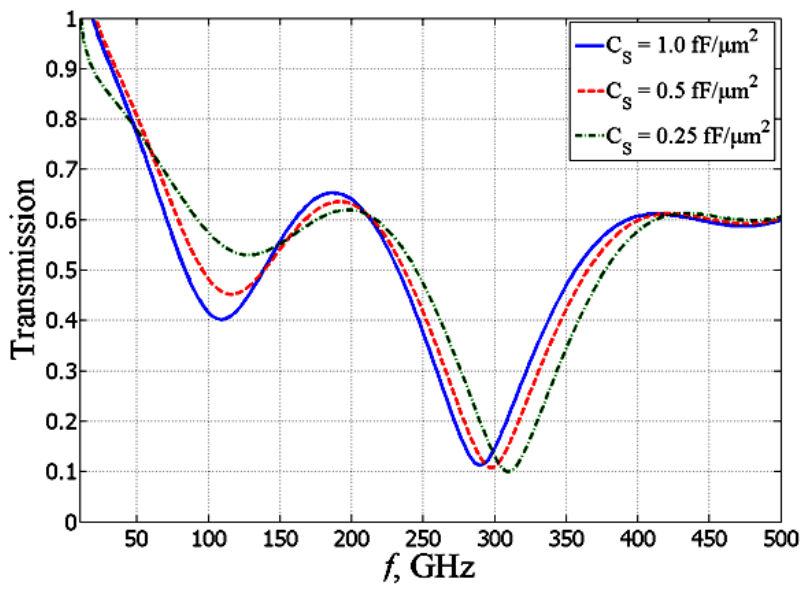

Fig. 5. Transmission spectra of the varactor-loaded SRR with different depletion capacitance of Schottky barrier. $A=150 \mu \mathrm{m}, W=4 \mu \mathrm{m}, G=2 \mu \mathrm{m}$, cell $=170 \mu \mathrm{m}, 350 \mu \mathrm{m}$ GaAs substrate.

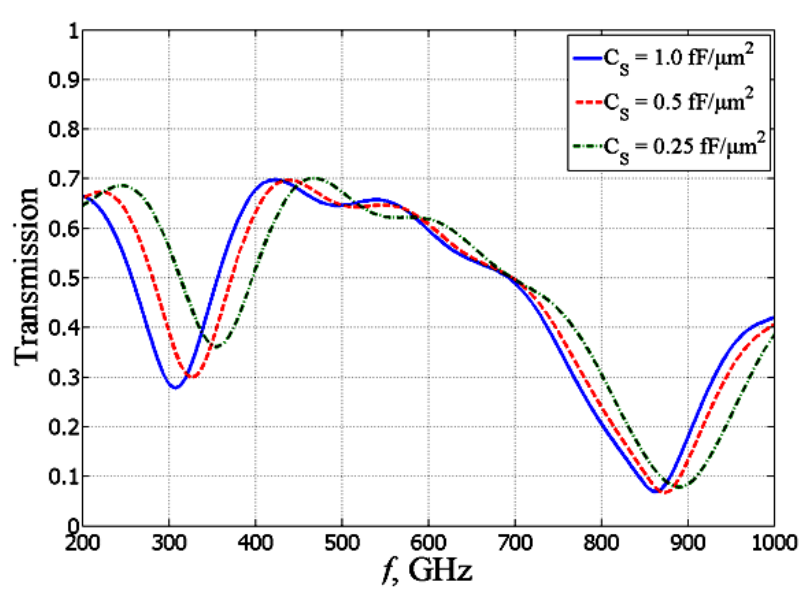

Fig. 6. Transmission spectra of varactor-loaded SRR with different depletion capacitance of Schottky barrier. $A=56 \mu \mathrm{m}, W=4 \mu \mathrm{m}, G=2 \mu \mathrm{m}$, cell $=70 \mu \mathrm{m}, 350 \mu \mathrm{m}$ GaAs substrate.

$300 \mathrm{GHz}$ by reducing the SRR size (parameter $A$ ) and the unit cell size. In this case, the serial resonance frequency shifts by $15.6 \%$ and the amplitude of the transmitted signal changes roughly by $25 \%$ when decreasing varactors capacitance in the same range as in the case of the parallel resonance. Both examples considered here demonstrate that the SRRs loaded with a high-frequency Schottky barrier varactor permit effective tuning of the filter central frequency in the region around $300 \mathrm{GHz}$. The tunable filters may be operated at still higher frequencies as the cut-off frequency of high-frequency Schottky varactors normally exceeds $1 \mathrm{THz}$ [14]. 


\section{Conclusions}

The band-stop filtering effect in the transmission spectrum is considered by the current modes in the stripes of the SRR. Two fundamental types of current modes are distinguished: parallel and serial. The parallel mode is induced by the external electric field whereas the serial mode appears only in asymmetric structures as a LC oscillation when the external field disappears. The resonance frequency of the SRR can be predicted from the size of the segments of the SRR. By electrically depleting the Schottky barrier varactor, which is loaded in the SRR array, one can tune the central frequency of the filter enabling modulation capability in the region around $300 \mathrm{GHz}$.

\section{References}

[1] D.R. Smith, W.J. Padilla, D.C. Vier, S.C. NematNasser, and S. Schultz, Phys. Rev. Lett. 84, 18 (2000).

[2] W.J. Padilla, A.J. Taylor, C. Highstrete, M. Lee, and R.D. Averitt, Phys. Rev. Lett. 96, 107401 (2006).

[3] D. Schurig, J.J. Mock, and D.R. Smith, Appl. Phys. Lett. 88, 041109 (2006).

[4] J.F. O’Hara, E. Smirnova, H.-T. Chen, A.J. Taylor, R.D. Averitt, C. Highstrete, M. Lee, and A.J. Padilla, J. Nanoelectron. Optoelectron. 2, 90 (2007).
[5] E. Ekmekci, A.C. Strikwerda, K. Fan, G. Keiser, X. Zhang, G. Turhan-Sayan, and R.D. Averitt, Phys. Rev. B 83, 193103 (2011).

[6] H.-T. Chen, W.J. Padilla, J.M.O. Zide, A.C. Gossard, A.J. Taylor, and R.D. Averitt, Nature Lett. 444, 597 (2006).

[7] H.-T. Chen, S. Palit, T. Tyler, C.M. Bingham, J.M.O. Zide, J.F. O’Hara, D.R. Smith, A.C. Gossard, R.D. Averitt, W.J. Padilla, N.M. Jokerst, and A.J. Taylor, Appl. Phys. Lett. 93, 091117 (2008).

[8] D. Shrekenhamer, S. Rout, A.C. Strikwerda, C. Bingham, R.D. Averitt, S. Sonkusale, and W.J. Padilla, Opt. Express 10, 9968 (2011).

[9] H.-T. Chen, W.J. Padilla, J.M.O. Zide, S.R. Bank, A.C. Gossard, A.J. Taylor, and R.D. Averitt, Opt. Lett. 32, 1620 (2007).

[10]H.-T. Chen, J.F. O’Hara, A.K. Azad, A.J. Taylor, R.D. Averitt, D.B. Shrekenhamer, and W.J. Padilla, Nat. Photon. 2, 295 (2008).

[11] W. Withayachumnankul, C. Fumeaux, and D. Abbott, IEEE Antenn. Wireless Propag. Lett. 10, 577 (2011).

[12]A. Taflove and S.C. Hagness, Computational Electrodynamics: The Finite-Difference TimeDomain Method (Artech House, Norwood, 2000).

[13] ̌̌. Kancleris, G. Šlekas, and A. Matulis, IEEE Trans. Antenn. Propag. 61, 994 (2013).

[14] T.J. Tolmunen and M.A. Frerking, in: Second Int. Symp. Space Terahertz Technol. (1991), p. 197.

[15] T.W. Crowe, W.C.B. Peatman, and W.L. Bishop, in: First Int. Symp. Space Terahertz Technol. (1990), p. 256.

\title{
ŽIEDINIŲ REZONATORIŲ MATRICOS REZONANSINIO DAŽNIO DERINIMAS TERAHERCŲ RUOŽE
}

\author{
G. Šlekas, Ž. Kancleris, D. Seliuta \\ Fiziniu ir technologijos mokslu centras, Vilnius, Lietuva
}

\footnotetext{
Santrauka

Baigtinių skirtumų laiko skaleje metodu buvo tirtos atskirų simetrinių ir asimetrinių žiedelių ir plokščios tokių žiedelių matricos, suformuotos ant dielektrinès plokštelès, savybès. Nustatyti tokių darinių srovès rezonansų tipai. Ištirtas ryšys tarp matricos filtravimo
}

savybių ir srovés rezonansų atskirame žiedelyje. Nustatyta rezonansinio dažnio priklausomybè nuo žiedelio matmenų. Keičiant prijungto prie žiedelio Šotkio (Schottky) barjero nuskurdintos srities talpą, pademonstruota galimybė valdyti žiedelių matricos rezonansinį dažnị. 